\title{
CORRIGENDUM
}

\section{Linear models of economic survival under production uncertainty}

\author{
Mukul Majumdar ${ }^{1}$ and Roy Radner ${ }^{2}$ \\ 1 Department of Economics, Cornell University, Ithaca, NY 14853, USA \\ 2 Department of Economics, New York University, and, A.T. \& T. Bell Laboratories, \\ 600 Mountain Avenue, Murray Hill, NJ 07974, USA
}

The appendix in Majumdar and Radner [1] contains some misprints that are corrected below.

- Equation (0.9) on page 28 should read:

$$
\min _{v \in\left[v^{\prime}, v^{\prime \prime}\right]} A \psi(y)=0 \text { for } 0<y<d ; \lim _{y \backslash 0} \psi(y)=1, \lim _{y \uparrow d} \psi(y)=0 .
$$

- On page 29 , in line 7 from the top one should read: "If possible, let $\max u(y)$ be..."

- On page 29 , in line 14 from the top one should read: " $u(y)+\epsilon Q(y)$, where..."

- On page 29 in line 19 from the top one should read " $y \in(0, d) . "$

- On page 29 , equation (0.16) should read:

$$
\bar{\mu}(y)=\left[f(\bar{v}(y))+\frac{1}{2} \bar{v}(y)\right] y-c, \quad \text { and } \quad \bar{v}(y),
$$

\section{References}

1. Majumdar M, Radner R (1991) Linear models of economic survival under production uncertainty. Econom Theory 1:13-36 